\title{
Sperm head length as a predictor of fecundity in the sandhill crane, Grus canadensis
}

\author{
J. S. Sharlin*, C. S. Shaffner and G. F. Gee $\dagger$ \\ Department of Poultry Science, University of Maryland, College Park, Maryland 20742, and \\ $\uparrow$ Patuxent Wildlife Research Center, U.S. Fish and Wildlife Service, Laurel, Maryland 20311, \\ U.S.A.
}

Summary. Semen samples from 14 sandhill cranes were collected for 15 weeks. Mean sperm head length which did not vary significantly over weeks was found to be significantly correlated with fertility $(P<0.04 ; r=0.54, n=14)$.

\section{Introduction}

Several investigators are breeding the sandhill crane (Grus canadensis) in captivity. A test capable of predicting male fecundity before permitting pair bond formation would aid this effort. Most semen evaluation tests are impractical because of low sperm concentration (0.2-1.0 $\times 10^{6}$ per $\mathrm{ml})$ and volume $(0.05 \mathrm{ml})$ of semen per ejaculate in cranes (G. Gee, unpublished observations).

Of various sperm structural defects, head abnormalities have been shown to reveal the most about potential fertilizing ability in man (Moench \& Holt, 1931) and fowl (Kamar \& Badreldin, 1959). A significant correlation between an increase in sperm head malformations and a decrease in sperm concentration, motility and percentage of live spermatozoa was shown for turkey semen (Kamar \& Rizik, 1972). Sperm head length has been positively correlated with conception rate in bulls (Mukerjee \& Kumar, 1971). The variability of sperm head length, as measured by the coefficient of variation (C.V.), has been negatively correlated with fertility in bulls (Williams \& Savage, 1925; Savage, Williams \& Fowler, 1927) and horses (Savage, Williams \& Fowler, 1930). The purpose of this study was to determine whether sperm head length could be an appropriate test for prediction of fecundity in the sandhill crane.

\section{Materials and Methods}

Semen samples from 14 sandhill cranes housed at Patuxent Wildlife Research Center with a territory and a mate were collected twice each week from the beginning of March to the first week in June. Four subspecies, the Florida sandhill crane (Grus canadensis pratensis), greater sandhill crane (G. c. tabia), lesser sandhill crane (G. c. canadensis) and Mississippi sandhill crane (G. c. pulla) were sampled. Semen was collected using the technique described by Archibald (1974). More than half of the semen sample was used for artificial insemination (A.I.), the remainder was kept for evaluation. A modification of the staining technique of Casarett (1953) was used (Sharlin, 1976) to prepare slides for semen evaluation. On each slide 10 spermatozoa were measured using a light microscope at $\times 2500$ equipped with an occular micrometer. Sperm head length was defined as the distance between the proximal centriole and the posterior border of the acrosome. From the 10 observations of each slide (the experimental unit), two dependent variables were calculated, the mean and the C.V. of sperm head length.

\footnotetext{
* Present address: Department of Poultry Science, University of Georgia, Athens, Georgia 30602, U.S.A.
} 
Measurements of reproductive potential (fecundity) were calculated from totals of 3 years of egg data taken while A.I. was used to augment natural mating. All natural mating and A.I. occurred between pair bonded mates. The fecundity parameters, expressed as quotients multiplied by 100 , were hatchability (number hatched/number incubated), fertility (number fertile/number incubated) and viability (number hatched/number fertile).

The first 2 weeks of data were omitted from all analyses because ejaculates collected after a long period of sexual inactivity may contain degenerate spermatozoa. Data for the analyses were taken from an average of 19 slides per male. Using an average slide value of individual males, subspecies differences in sperm measurements, i.e. mean and C.V., were analysed using a oneway analysis of variance (ANOVA) and Student-Newman-Kuel's (S.N.K.) test at the 0.05 level (Steel \& Torrie, 1960). Weekly variation in sperm measurements was examined separately for each subspecies using a mixed model in a two-way design. Birds represented the random factor and weeks were fixed. Tests of significance were conducted according to Scheffe (1959). The analysis of weekly variation was conducted on the mean and C.V. of 10 observations from each slide using a least-squares computer programme able to accommodate unequal replication (Barr, Goodnight, Sall \& Helwig, 1976). The sensitivity of the ANOVA on weekly variation was calculated using a $90 \%$ power of the test and an alpha level of 0.05 (Cochran \& Cox, 1957). Subspecies differences for fecundity were examined using the Kruskal-Wallis test (Steel \& Torrie, 1960). Spearman correlations were calculated between sperm measurements and fecundity variables. Data from all pairs were combined and used in the correlations with fertility and hatchability. Three pairs which had produced fewer than 3 fertile eggs were not used in the correlations with viability.

\section{Results}

There were significant differences between subspecies $(P<0.01)$ for sperm head length (Table 1). The greater sandhill crane had a significantly longer sperm head length than the lesser and Mississippi sandhill cranes. The Florida sandhill crane had a significantly longer sperm head length than the lesser sandhill crane. Mean sperm head length ranged from 10.8 to $14.4 \mu \mathrm{m}$ which overlaps the 9-12 $\mu \mathrm{m}$ range reported for the turkey (Wakely \& Kosin, 1951). There were no significant differences between subspecies $(P<0.10)$ for the C.V. of sperm head length (Table 1). Significant differences did not exist between weeks $(P<0.50)$ for mean sperm head length and C.V. The sensitivity for the ANOVA for weekly differences ranged from $1.12 \mu \mathrm{m}$ (lesser sandhill crane) to $1.99 \mu \mathrm{m}$ (Mississippi sandhill crane) for the mean length and from $3.82 \%$ (greater sandhill crane) to $7.30 \%$ (lesser sandhill crane) for the C.V. The Kruskal-Wallis test revealed no significant differences between subspecies for any measurement of fecundity

Table 1. Measurements (mean \pm s.e.m.) of fecundity and sperm head length from four subspecies of sandhill crane

\begin{tabular}{|c|c|c|c|c|c|c|c|}
\hline \multirow[b]{2}{*}{ Subspecies* } & \multirow{2}{*}{$\begin{array}{c}\text { No. of } \\
\text { eggs } \\
\text { incubated }\end{array}$} & \multicolumn{3}{|c|}{ Fecundity $\dagger$} & \multirow{2}{*}{$\begin{array}{c}\text { No. of } \\
\text { spermatozoa } \\
\text { observed }\end{array}$} & \multicolumn{2}{|c|}{ Sperm head length } \\
\hline & & $\begin{array}{c}\text { Fertility } \\
(\%)\end{array}$ & $\begin{array}{c}\text { Hatchability } \\
(\%)\end{array}$ & $\begin{array}{l}\text { Viability } \\
\text { (\%) }\end{array}$ & & Mean $\ddagger$ & $\begin{array}{l}\text { C.V. } \\
(\%)\end{array}$ \\
\hline Florida (5) & $28 \pm 1 \cdot 5$ & $46 \cdot 9 \pm 11 \cdot 2$ & $31.8 \pm 10 \cdot 5$ & $63 \cdot 2 \pm 6 \cdot 6$ & $214 \pm 6$ & $a, b 13.0 \pm 0.3$ & $10 \cdot 1 \pm 0.7$ \\
\hline Greater (5) & $16 \pm 1.4$ & $60.6 \pm 10.8$ & $36.6 \pm 9.4$ & $56 \cdot 2 \pm 6 \cdot 0$ & $188 \pm 17$ & ${ }^{b} 13.8 \pm 0.3$ & $11.0 \pm 0.8$ \\
\hline Lesser (2) & $6.5 \pm 0.4$ & $7 \cdot 15 \pm 5 \cdot 0$ & $7 \cdot 15 \pm 5 \cdot 0$ & - & $180 \pm 40$ & $c_{11.4 \pm 0.5}$ & $9.8 \pm 1.3$ \\
\hline Mississippi (2) & $14 \cdot 5 \pm 3 \cdot 9$ & $23 \cdot 6 \pm 1 \cdot 0$ & $10.5 \pm 0.4$ & $40 \S$ & $150 \pm 30$ & a,c $12.1 \pm 0.5$ & $9 \cdot 0 \pm 1 \cdot 1$ \\
\hline
\end{tabular}

* Figures in parentheses indicate the number of mated pairs; the average for each pair was used to obtain the mean for the subspecies.

$\uparrow$ Based on total number of eggs laid during a 3-year period.

$\ddagger$ Means with different superscripts are significantly different at the $5 \%$ level by the S.N.K. test.

$\S$ Value for one mated pair. 
(Table 1). Mean sperm head length had a significant positive correlation with fertility $(P<0.04$; $r=0.54)$ but not with hatchability $(P<0.08 ; r=0.48)$ or viability $(P<0.50 ; r=0.23)$.

There was no evidence that the C.V. of sperm head length was correlated with fertility $(P<0.93 ; r=0.02)$, hatchability $(P<0.95 ; r=0.01)$ or viability $(P<0.15 ; r=0.46)$. Negative correlations were expected between the C.V. and all measures of fecundity.

\section{Discussion}

Sperm head length has potential as a predictor of fertility and hatchability. The C.V. probably has no value as a predictor of fecundity. By permitting additional bends and twists of the sperm cell as it attempts to penetrate the inner layer of the vitelline membrane (Fujii, 1976), a longer sperm head length could account for increased fertility. The high heritability of sperm head length in rabbits (Beatty, 1972) implies that selection for increased fertility and hatchability based on this characteristic will probably be successful with cranes.

The sensitivity of the ANOVA on mean sperm head length indicates that each subspecies as a group exhibited small amounts of week-to-week variation. Since fecundity prediction is applied to a single bird, weekly variation of individuals is important. A particular male within a subspecies may exhibit more weekly variation than the subspecies average. The range of weekly means for an individual male averaged $2.5 \mu \mathrm{m}$, whereas the range of the weekly subspecies means was $2.4 \mu \mathrm{m}$. Therefore, a single semen sample might give an unrepresentative value for a male. Depending on the amount of individual weekly variation, mean sperm head length for a male should be based on an average of several semen samples.

This work was supported partly by a grant from Sigma Xi.

\section{References}

Archibald, C.W. (1974) Methods for breeding and rearing cranes in captivity. Int. Zoo $Y b$. 14, 147-155.

Barr, A.J., Goodnight, J.H., Sall, J.P. \& Helwig, J.T. (1976) The General Linear Models (GLM) Procedure. In $A$ Users Guide to $S A S$ 76, pp. 127-144. SAS Institute, Raleigh, North Carolina.

Beatty, R.A. (1972) The genetics of size and shape of spermatozoan organelles. In The Genetics of the Spermatozoon, pp. 97-115. Eds R. A. Beatty \& S. Gluecksohn-Waelsch. Beatty \& GluecksohnWaelsch, Edinburgh.

Casarett, G.W. (1953) A one solution stain for spermatozoa. Stain Technol. 28, 125-127.

Cochran, W.G. \& Cox, G.M. (1957) Experimental Designs, 2nd edn, pp. 17-23. Wiley \& Sons, New York.

Fujii, S. (1976) Scanning electron microscopical observation on the penetration mechanism of fowl spermatozoa into the ovum in the process of fertilization. $J$. Fac. Fish. Anim. Husb. Hiroshima Univ. 15, 85-92.

Kamar, G.A.R. \& Badreldin, A.L. (1959) Sperm morphology and viability. Acta anat. 39, 81-83.

Kamar, G.A.R. \& Rizik, M.A.A. (1972) Semen characteristics of two breeds of turkeys. J. Reprod. Fert. 29, 317-325.

Moench, G.L. \& Holt, H. (1931) Sperm morphology in relation to fertility. Am. J. Obstet. Gynec. 22, 199210 .
Mukerjee, D.P. \& Kumar, R. (1971) Morphology of bull spermatozoa in relation to fertility. Indian J. Anim. Sci. 41, 218-222.

Savage, A., Williams, W.W. \& Fowler, N.M. (1927) A statistical study of the head length variability of bovine spermatozoa and its application to the determination of fertility. Trans. R. Soc. Can., Section V 21, 425-450.

Savage, A., Williams, W.W. \& Fowler, N.M. (1930) A study of the head length variability of equine spermatozoa. Can.J. Res. 3, 327-335.

Scheffe, H. (1959) The Analysis of Variance, p. 269. Wiley \& Sons, New York.

Sharlin, J.S. (1976) Sperm head length as a predictor of fecundity in the sandhill crane. Masters thesis, University of Maryland, College Park, Maryland.

Steel, R.G.D. \& Torrie, J.H. (1960) Principles and Procedures in Statistics, pp. 110-111, 406-407. McGraw-Hill, New York.

Wakely, W.J. \& Kosin, I.L. (1951) A study of morphology of the turkey spermatozoa with special reference to the seasonal prevalence of abnormal types. Am. J. vet. Res. 12, 240-245.

Williams, W.W. \& Savage, A. (1925) Observations on the seminal micropathology of bulls. Cornell Vet. 15, $353-374$. 